\title{
Estudo antropométrico e dietético de nadadores competitivos de áreas metropolitanas da região sudeste do Brasil*
}

\author{
Anthropometric and dietetic study of competitive swimmers of metropolitan areas of \\ southeastern Brazil
}

Eliane A. Soares ${ }^{\star \star}$, Midori Ishii ${ }^{\star \star \star}$, Roberto C. Burini ${ }^{\star \star \star \star}$

SOARES, E.A. et al. Estudo antropométrico e dietético de nadadores competitivos de áreas metropolitanas da região sudeste do Brasil. Rev. Saúde Pública, 28: 9-19, 1994. Com o objetivo de caracterizar os ábitos alimentares de nadadores competitivos de dois clubes das cidades do Rio de Janeiro e de São Paulo, foram estudados atletas, 30 homens e 37 mulheres pertencentes às equipes juvenil (15-17 anos) e "seniors" (18-25 anos). Concomitantemente à avaliação antropométrica, foi feito o inquérito alimentar mediante os métodos de registro alimentar, recordatório de 24 horas e freqüência de consumo alimentar. Os resultados mostraram semelhança antropométrica entre as duas faixas etárias para cada um dos sexos, semelhança dos alimentos prevalentemente ingeridos com aqueles referidos pela população da área metropolitana das duas cidades e semelhança entre os suplementos alimentares ingeridos pelos atletas dos dois clubes. A ingestão calórica observada foi quase o dobro da referida para a população daquelas localidades, mas equivalente à descrita para nadadores de outros paises. Os lanches, entre refeiçōes, contribuiram com $25-28 \%$ da ingestão calórica global e a maior contribuição energética alimentar foi dada pelo grupo de cereais. Apesar de contribuir com quase $50 \%$ do aporte calórico diário, a ingestão glicídica foi menor que a recomendada para atletas competitivos (55-60\%). A ingestão protéica de $2,5-3,0 \mathrm{~g} / \mathrm{kg} /$ dia superou em $100 \%$ o valor recomendado para atletas e ultrapassou os $15 \%$ na participação calórica diária. A ingestão lipídica foi considerada elevada, particularmente a de gordura saturada. $O$ aporte de micronutrientes foi acima do referido para as populações locais em função da ingestão calórica elevada, mas mostrou-se relativamente inadequado em magnésio, ferro e vitaminas $A$ e D. Conclui-se que o padrão alimentar dos nadadores estudados não difere, muito, do da população local, distinguindo-se pelo elevado e freqüente consumo de alimentos energéticos, maior no sexo masculino que no feminino.

Descritores: Hábitos alimentares, classificação. Inquéritos sobre dietas. Natą̧ão.

\section{Introdução}

Excluídos os componentes hereditários e o condicionamento atlético, nenhum outro fator isolado ocupa papel mais importante que a nutrição no desempenho físico do atleta ${ }^{11}$. Assim, nota-se a

* Resumo da Tese de Doutorado apresentada à Faculdade de Ciências Farmacêuticas da Universidade de São Paulo, em 1992.

** Instituto de Nutrição da Universidade do Estado do Rio de Janeiro e Universidade Federal do Rio de Janeiro - Rio de Janeiro, RJ - Brasil

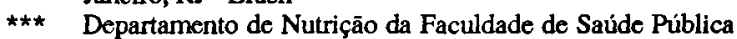
da Universidade de São Paulo - São Paulo, SP - Brasil

$\star \star \star \star$ Departamento de Clínica Médica da Faculdade de Medicina da Universidade Estadual de São Paulo - Botucatu, SP . Brasil

Separatas/Reprints: R.C.Burini - 18618-000 - Botucatu, SP - Brasil Edição subvencionada pela FAPESP. Processo 94/0500-0. partir dos anos 60 o aumento no número de publicações relativas ao melhor conhecimento da nutrição do atleta. Esses esforços vêm sendo direcionados, essencialmente, em dois objetivos: $1^{9}$ ) conhecer os efeitos da atividade física sobre os requerimentos nutricionais do individuo; $2^{9}$ ) conhecer os efeitos potencializadores da dieta na melhoria do desempenho atlético ${ }^{3}$. As conclusões já divulgadas permitem o consenso de que não há possibilidade da orientação nutricional única para todos os atletas. A heterogenidade das modalidades esportivas e suas peculiaridades metabólico-energéticas selecionam o uso e as perdas de nutrientes específicos e, portanto, suas necessidades. Assim, vem se avolumando o número de trabalhos contendo informações nutricionais mais profundas, sobre cada uma das modalidades esportivas. Mesmo assim, nota-se, principalmente no Brasil, a falta desses conhecimentos específicos, tanto para os atletas ${ }^{11}$ como 
para seus treinadores ${ }^{44}$. Essa falta de conhecimento é agravada, invariavelmente, pela vigência de hábitos nutricionais fundamentados em superstições ${ }^{39}$, conselhos de amigos ou reportagens em imprensa leiga ${ }^{36}$.

Em relação a atletas nadadores muito se tem divulgado, principalmente no exterior, sobre suas maiores necessidades nutricionais, em virtude do contacto com a água ${ }^{15}$ e com a atividade física "per se". Entretanto, antes de se prescrever a dieta adequada a esses atletas, seria importante conhecer um pouco mais o que os atletas de sucesso, nesta modalidade, consomem. $O$ presente trabalho tem por objetivo caracterizar os hábitos dietéticos e quantificar a ingestão alimentar de atletas competitivos de clubes brasileiros das cidades de São Paulo e Rio de Janeiro, localizados na região sudeste do Brasil.

\section{Casuística e Métodos}

Participaram do estudo 67 atletas, 30 do sexo masculino e 37 do feminino, de idades entre 15-26 e 15-24 anos, respectivamente, voluntários e filiados a um clube de São Paulo (34 atletas) e a outro do Rio de Janeiro (33 atletas).

Os indivíduos estudados pertenciam aos estratos sociais: classe média superior e classe alta ${ }^{40} . \mathrm{Na}$ ocasião do estudo, ambos os grupos de atletas encontravam-se em período de treinamento intensivo, matutino e vespertino, totalizando 10 treinos semanais de 3-4 horas cada.

As medidas antropométricas foram realizadas em 51 atletas, tendo sido registrados peso e estatura com os quais calculou-se o indice de Quetelet ${ }^{1,2}$. Além desses, foram avaliadas sete pregas cutâneas (biceps, triceps, subescapular, suprailiaca, axilar média, abdominal e panturrilha), avaliadas do lado direito do corpo, em triplicata, registrando-se o valor médio ${ }^{1,2}$. A percentagem de gordura corporal foi calculada a partir da somatória das pregas cutâneas aplicando-se as equações de Faulkner ${ }^{19}$ e de Brozek \& Keys 5 . Foram medidas também as circunferências da coxa e do braço e, a partir deste último dado, descontado o valor da prega cutânea tricipital foi calculada a circunferência muscular do braço $^{1,2}$.

Para o estudo dietético foram empregados os métodos ${ }^{2}$ : recordatório de 24 horas, registro alimentar de dois dias e questionário de freqüência alimentar. O primeiro e o terceiro métodos foram aplicados por um único pesquisador e o segundo, preenchido pelo próprio atleta após instrução prévia e com assessoria periódica do pesquisador. As medidas caseiras foram convertidas em gramas e mililitros $^{41}$ e a quantificação dos nutrientes foi feita mediante programa computadorizado fornecido pelo Centro de Informática em Saúde da Escola Paulista de Medicina ${ }^{18}$. As ingestões de suplementos dietéticos e drogas ${ }^{21,22}$ também foram registradas.

Para efeito de análise estatística os atletas foram divididos de acordo com o sexo e idades correspondentes à categoria de competição, ou seja, juvenil (15-18 anos) e senior (>18 anos).

O contraste estatístico entre médias de grupos foi feito pelo teste " $t$ de Student", e quando não confirmada a significância estatística foram agrupados os valores e calculados os percentis.

\section{Resultados}

Nào houve, em ambos os sexos, diferença estatisticamente significante entre as duas faixas etárias estudadas (Tabelas 1 e 2), permitindo que os dados antropométricos fossem agrupados para cada sexo.

A análise da ingestão alimentar quantificada nos dois métodos utilizados não mostrou diferença estatística optando-se então pelo uso dos valores do recordatório de 24 horas para cálculo da ingetão dos macronutrientes e micronutrientes (Tabela 3 ).

Quanto aos tipos de refeições diárias, $100 \%$ dos atletas, de ambos os sexos, referiram fazer desjejum e almoço, 95\% dos rapazes e $94 \%$ das moças faziam jantar, $77 \%$ e $73 \%$, respectivamente, faziam lanche vespertino, sendo que a colação foi referida por $52 \%$ dos rapazes e $51 \%$ das moças. A ceia noturna foi a sexta refeição diária cuja freqüência foi de $9 \%$ para as atletas femininas e o dobro para os masculinos.

Os alimentos mais referidos como sendo de consumodiário encontram-se na Tabela 4 , enquanto que os suplementos dietéticos e drogas mais consumidos pelos nadadores encontram-se na Tabela 5.

Dentre os nadadores juvenis, a influência do sexo foi notada pela preferência das moças de São Paulo pela maçã, enquanto os rapazes preferiram laranja. Neste item, frutas, a preferida dos atletas do Rio de Janeiro, de ambos os sexos, foi a banana. Dentre os cereais, os atletas do sexo feminino e 
Tabela 1. Dados antropométricos de nadadores do sexo masculino distribuídos por faixa etária $(\bar{X} \pm s)$. Comparação entre faixas etárias: estatistica t e nivel de significância.

\begin{tabular}{|c|c|c|c|c|}
\hline \multirow{2}{*}{$\begin{array}{l}\text { Variáveis } \\
\text { Antropométricas }\end{array}$} & \multicolumn{2}{|c|}{ Idade (Anos) } & \multirow{2}{*}{ Valor de $\mathrm{t}$} & \multirow{2}{*}{$\begin{array}{c}\text { Significância } \\
\text { Estatística }\end{array}$} \\
\hline & $15-17$ & $>18$ & & \\
\hline Altura $(\mathrm{cm})$ & $180,3 \pm 8,2$ & $181,1 \pm 5,3$ & 0,22 & $P>0,50$ \\
\hline Peso $(\mathrm{kg})$ & $74,0 \pm 9,8$ & $74,0 \pm 5,4$ & 0 & $P=1,00$ \\
\hline $\mathrm{IQ}\left(\mathrm{kg} / \mathrm{m}^{2}\right)$ & $20,5 \pm 1,8$ & $20,5 \pm 1,2$ & 0 & $P=1,00$ \\
\hline $\mathrm{PCB}(\mathrm{mm})$ & $4,3 \pm 0,4$ & $3,8 \pm 0,7$ & 1,63 & $P>0,01$ \\
\hline PCT (mm) & $7,3 \pm 1,6$ & $6,8 \pm 2,0$ & 0,54 & $P>0,50$ \\
\hline PCSE (mm) & $8,4 \pm 1,5$ & $9,3 \pm 2,1$ & 0,95 & $P>0,30$ \\
\hline $\operatorname{PCSI}(\mathrm{mm})$ & $7,7 \pm 3,1$ & $7,4 \pm 2,0$ & 0,46 & $P>0,50$ \\
\hline PCAM (mm) & $6,4 \pm 1,5$ & $6,1 \pm 1,5$ & 0,41 & $P>0,50$ \\
\hline $\mathrm{PCA}(\mathrm{mm})$ & $9,2 \pm 2,7$ & $9,8 \pm 3,5$ & 0,38 & $P>0,50$ \\
\hline $\mathrm{PCP}(\mathrm{mm})$ & $8,0 \pm 1,8$ & $6,7 \pm 2,1$ & 1,33 & $P>0,10$ \\
\hline $\mathrm{PC}(\mathrm{mm})$ & $51,2 \pm 10,7$ & $49,8 \pm 10,8$ & 0,27 & $P>0,50$ \\
\hline$\%$ Gordura (Faulkner) & $10,8 \pm 1,2$ & $10,9 \pm 1,3$ & 0,20 & $P>0,50$ \\
\hline$\%$ Gordura (Brozek) & $16,3 \pm 2,4$ & $16,4 \pm 2,6$ & 0,09 & $P>0,50$ \\
\hline $\mathrm{CB}(\mathrm{cm})$ & $32,0 \pm 2,1$ & $33,0 \pm 1,6$ & 0,93 & $P>0,30$ \\
\hline $\mathrm{CP}(\mathrm{cm})$ & $34,7 \pm 1,1$ & $36,7 \pm 1,7$ & 1,92 & $P>0,05$ \\
\hline $\mathrm{CMB}(\mathrm{cm})$ & $29,7 \pm 2,1$ & $30,7 \pm 1,8$ & 0,85 & $P>0,30$ \\
\hline
\end{tabular}

$\mathbb{Q}=$ Índice de Queteletl, $\mathrm{PCB}=$ prega cutânea bicipital, $P C T=$ prega cutânea tricipital, $\mathrm{PCSE}$ = prega cutânea subescapular, $\mathrm{PCSI}=$ prega cutânea suprailíaca, $\mathrm{PCAM}=$ prega cutânea axilar média, $\mathrm{PCA}=$ prega cutânea abdominal, $\mathrm{PCP}=\mathrm{prega}$ cutânea da panturrilha, $\mathrm{PC}=$ somatória das pregas cutâneas, $\mathrm{CB}=$ circunferência braquial, $\mathrm{CP}=$ cinrcunferência de perna, $\mathrm{CMB}=$ circunferência muscular do braço.

Tabela 2. Dados antropométricos de nadadores do sexo feminino distribuídos por faixa etária $(\bar{X} \pm s)$. Comparação entre faixas etárias: estatística t e nivel de significância.

\begin{tabular}{|c|c|c|c|c|c|c|}
\hline \multirow{2}{*}{$\begin{array}{l}\text { Variáveis } \\
\text { Antropométricas }\end{array}$} & \multicolumn{4}{|c|}{ Idade (Anos) } & \multirow{2}{*}{ Valor de $t$} & \multirow{2}{*}{$\begin{array}{c}\text { Significância } \\
\text { Estatistica }\end{array}$} \\
\hline & \multicolumn{2}{|c|}{$15-17$} & \multicolumn{2}{|c|}{$>18$} & & \\
\hline Altura $(\mathrm{cm})$ & 166,6 & 6,7 & 166,0 & 8,0 & 0,21 & $P>0,50$ \\
\hline Peso $(\mathrm{kg})$ & 60,0 & 7,6 & $59,1=$ & 8,7 & 0,28 & $P>0,50$ \\
\hline $1 Q\left(\mathrm{~kg} / \mathrm{m}^{2}\right)$ & 18,0 & 1,9 & $17,7=$ & 2,1 & 0,36 & $P>0,50$ \\
\hline $\mathrm{PCB}(\mathrm{mm})$ & 6,7 & 2,3 & 6,4 & 2,0 & 0,33 & $P>0,50$ \\
\hline PCT (mm) & 13,4 & 3,0 & 12,8 & 5,0 & 0,40 & $P>0,50$ \\
\hline PCSE (mm) & 10,0 & 2,7 & 10,1 & 6,7 & 0,04 & $P>0,50$ \\
\hline $\mathrm{PCSI}(\mathrm{mm})$ & 9,5 & 2,8 & 9,4 & 6,6 & 0,04 & $P>0,50$ \\
\hline $\operatorname{PCAM}(\mathrm{mm})$ & 8,2 & 2,4 & 8,2 & 5,8 & 0 & $P=1,00$ \\
\hline $\mathrm{PCA}(\mathrm{mm})$ & 12,6 & 4,4 & 12,2 & 8,6 & 0,13 & $P>0,50$ \\
\hline $\mathrm{PCP}(\mathrm{mm})$ & 15,4 & 4,2 & 13,0 & 6,7 & 1,16 & $P>0,20$ \\
\hline$P C(\mathrm{~mm})$ & 74,7 & 17,4 & 72,2 & 39,5 & 0,17 & $P>0,50$ \\
\hline$\%$ Gordura (Faulkner) & 12,7 & 1,7 & 12,6 & 3,9 & 0,09 & $P>0,50$ \\
\hline$\%$ Gordura (Brozek) & 19,9 & 2,7 & $19,2=$ & 4,5 & 0,52 & $P>0,50$ \\
\hline $\mathrm{CB}(\mathrm{cm})$ & 28,1 & 2,4 & $29,1=$ & 2,7 & 0,82 & $P>0,40$ \\
\hline $\mathrm{CP}(\mathrm{cm})$ & 34,4 & 2,3 & 33,3 & 2,1 & 1,04 & $P>0,30$ \\
\hline $\mathrm{CMB}(\mathrm{cm})$ & 23,8 & 2,5 & 25,1 & 1,3 & 1,44 & $P>0,10$ \\
\hline
\end{tabular}

$\mathrm{IQ}=$ Índice de Quetelet, $\mathrm{PCB}=$ prega cutânea bicipital, $\mathrm{PCT}=$ prega cutânea tricipital, PCSE = prega cutânea subescapular, $P C S I=$ prega cutânea suprailiaca, $P C A M=$ prega cutânea axilar média, $P C A=$ prega cutânea abdominal, $P C P=$ prega cutânea da panturrilha, $\mathrm{PC}=$ somatória das pregas cutâneas, $\mathrm{CB}=$ circunferência braquial, $\mathrm{CP}=$ cinrcunferência de perna, $\mathrm{CMB}=$ circunferência muscular do braço. 
Tabela 3 - Consumo alimentar diário de macro e micronutrientes por nadadores competitivos. Distribuição quanto ao sexo e idade.

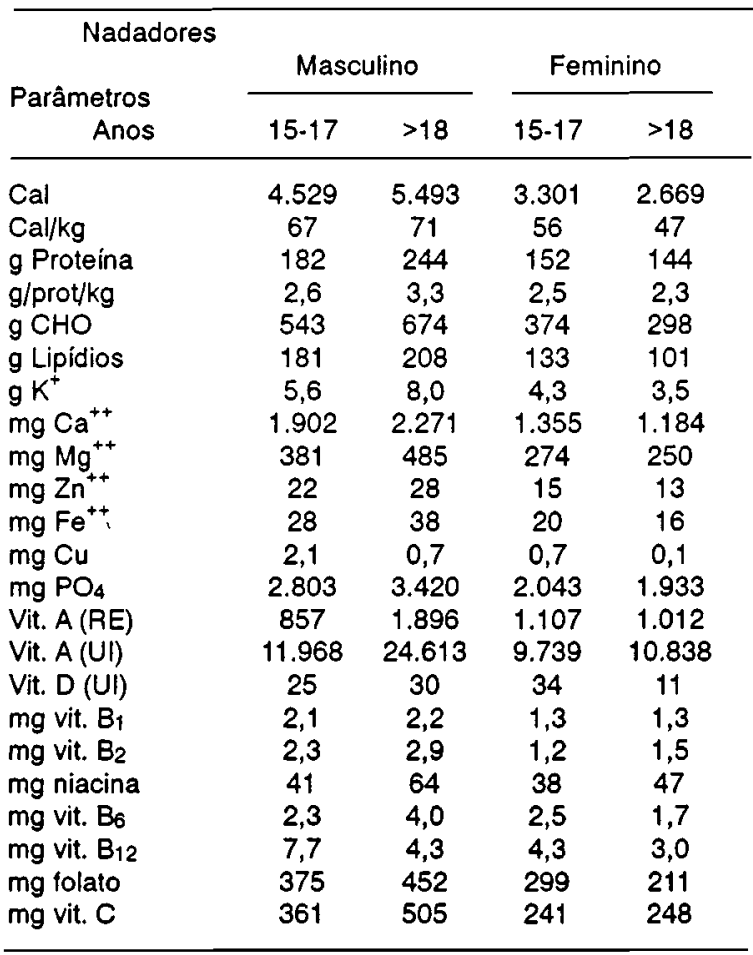

masculino (São Paulo e Rio de Janeiro) consomem o artoz, sendo que os do sexo masculino do Rio de Janeiro consomem também pão; chocolate foi o doce preferido das moças, enquanto os rapazes se dividiram entre geléia de frutas (Rio de Janeiro) e mel e gelatina (São Paulo).

Dentre os nadadores seniors, a influência do sexo foi notada pela preferência das moças, de

Tabela 4 - Alimentos mais prevalentes, referidos como de ingestão diária pelos nadadores.

\begin{tabular}{|c|c|}
\hline Grupos & Tipos \\
\hline carnes & de boi, de frango \\
\hline leite e produtos lácteos & leite, requeijāo \\
\hline ovos & de galinha \\
\hline hortaliças & $\begin{array}{c}\text { tomate, cenoura, alface, } \\
\text { batata inglesa }\end{array}$ \\
\hline leguminosas & feijão \\
\hline frutas & laranja, banana, maçã \\
\hline gorduras & manteiga, óleo de coccao \\
\hline doces & $\begin{array}{c}\text { chocolate, geléia de frutas, } \\
\text { mel, açúcar refinado }\end{array}$ \\
\hline liquidos & $\begin{array}{l}\text { sucos de frutas naturais, } \\
\text { vitaminas, mate }\end{array}$ \\
\hline
\end{tabular}

Tabela 5 - Suplementos alimentares e drogas mais referidos pelos nadadores.

\begin{tabular}{|c|c|c|c|c|}
\hline \multirow{2}{*}{ Consumo/Nadadores } & \multicolumn{2}{|c|}{ Masculino } & \multicolumn{2}{|c|}{ Feminino } \\
\hline & CSP & CRJ & CSP & CRJ \\
\hline \multicolumn{5}{|l|}{ Juvenil } \\
\hline Suplementos & sucrilhos & $\begin{array}{c}\text { musli, sustagem, } \\
\text { sucrilhos, granola, } \\
\text { meritene, fruta e } \\
\text { forca, sustacal }\end{array}$ & $\begin{array}{l}\text { sustagem, farinha } \\
\text { láctea, neston, } \\
\text { sucrilhos }\end{array}$ & $\begin{array}{l}\text { sustagem, farinha } \\
\text { láctea, sucrilhos }\end{array}$ \\
\hline Drogas & & biogerme & fibrax, all-bran & $\begin{array}{l}\text { levedura de cerveja, } \\
\text { guaraná em pó }\end{array}$ \\
\hline \multicolumn{5}{|l|}{ "Senior" } \\
\hline Suplementos & $\begin{array}{c}\text { musli, farinha } \\
\text { láctea, sustagem }\end{array}$ & $\begin{array}{c}\text { musli, sustagem, } \\
\text { granola, farinha } \\
\text { láctea, cereais } \\
\text { kellogs, gelatina } \\
\text { dietética }\end{array}$ & musli, sucrilhos & sustagem \\
\hline
\end{tabular}

Drogas

CSP = Clube de São Paulo

CRJ = Clube do Rio de Janeiro fibrax, all-bran

fibrax 
Tabela 6. Percentagem de calorias oriundas das proteínas, glicidios e lipídeos no consumo calórico total médio dos nadadores, de acordo com o sexo.

\begin{tabular}{lcc}
\hline & \multicolumn{2}{c}{ Sexo } \\
\cline { 2 - 3 } Macro & Masculino & Feminino \\
\hline Proteinas & $17,0 \%$ & $19 \%$ \\
Glicidios & $48,6 \%$ & $46 \%$ \\
Lipidios & $34,4 \%$ & $35 \%$ \\
AG sat & $13,5 \%$ & $11,2 \%$ \\
AG poli & $3,3 \%$ & $2,7 \%$ \\
AG mono & $5,4 \%$ & $4,7 \%$ \\
\hline
\end{tabular}

ambos os clubes, pela laranja enquanto os rapazes preferiram a banana.

Preferencialmente, as moças do Rio de Janeiro ingerem carne de frango, enquanto que os rapazes do Rio de Janeiro, assim com os rapazes e moças de São Paulo ingerem carne de boi. No mais, houve unanimidade no consumo de leite, requeijão, ovos e feijão.

A ingestão de fibras industrializadas caracterizou o grupo feminino de ambos os clubes; musli, sucrilhos e sustagem foram os suplementos mais referidos pelos atletas de São Paulo sendo que os do Rio de Janeiro apresentaram uma lista mais rica de suplementos, particularmente os atletas dos sexo masculino.

A percentagem de calorias oriundas das proteínas, glicídios e lipídios, na ingestão calórica diária total, encontram-se na Tabela 6 . Verifica-se que, em ambos os sexos, a contribuição dos carboidratos foi abaixo de $50 \%$, a das proteínas acima de $15 \%$ e a dos lipídios acima de $30 \%$. A contribuição de cada grupo de alimento ingerido para com o aporte energético diário encontra-se na Figura 1. Nota-se que os valores observados para ambos os sexos foram muito semelhantes, sendo que o maior percentual do aporte energético foi feito às custas dos cereais consumidos, e a contribuição calórica das frutas ultrapassou a dos açúcares.

Mais da metade (55\%) da ingestão energética diária ocorreu até o almoço, de modo diferenciado entre os sexos, já que a maior ingestão energética (6\%) no almoço das moças foi compensada pela maior densidade energética das demais refeições matinais dos rapazes. A ingestão energética vespertina e noturna foi semelhante entre os dois sexos.

\section{Discussão}

Os resultados antropométricos observados no presente trabalho (Tabelas 1 e 2 ) foram próximos aos existentes na literatura usando amostragem e metodologia semelhantes ${ }^{16,17,28,32,47}$. Como esperado ${ }^{46}$, as atletas femininas apresentaram percentual de adiposidade maior que os do sexo masculino, enquanto que o inverso ocorreu para índice de Quetelet, o que é atribuído à maior proporção de massa muscular existente nos rapazes 1 .

O estudo dietético envolveu a aplicação de três métodos distintos, visto a inexistência de um método dietético ideal, mas sim, preferencial ${ }^{4}$, uma vez que os métodos utilizados sempre apresentam vantagens e desvantagens ${ }^{20}$. Assim, foi utilizado o método recordatório de 24 horas, cuja maior crítica, no caso, seria que o dado de um único dia não representa, necessariamente o consumo dietético do indivíduo ${ }^{34}$. Portanto, foi feito também o registro alimentar, preenchido pelo próprio atleta, metodologia convencionalmente utilizada ${ }^{43}$ e com grande credibilidade no presente caso, visto ser a amostra

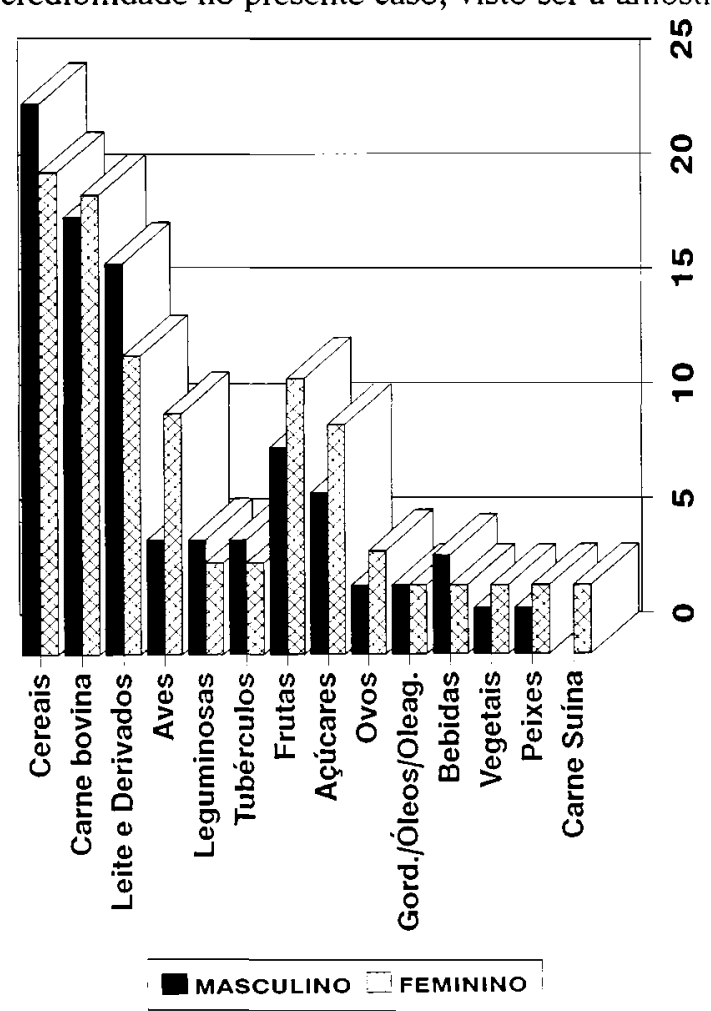

Figura 1. Contribuição percentual dos grupos de alimentos no consumo energético diário de atletas nadadores de ambos os sexos. 
Tabela 7. Consumo médio de energia e nutrientes obtido nas populaçōes metropolitanas do Rio de Janeiro e de Sāo Paulo (IBGE, 1979) e dos nadadores do presente trabalho.

\begin{tabular}{lccc}
\hline & \multicolumn{3}{c}{ Consumo } \\
\cline { 2 - 4 } Nutrientes & $\begin{array}{c}\text { Dados } \\
\text { obtidos }\end{array}$ & Dados IBGE 1979 \\
\cline { 2 - 4 } & & RJ & SP \\
\hline Kcal/d & 4.110 & 2.133 & 2.179 \\
Lipidios (g/d) & 153 & 59 & 65 \\
Glicidios (g/d) & 499 & 339 & 338 \\
Proteínas (g/d) & 192 & 68 & 66 \\
Lisina (mg/d) & 12.007 & 4.323 & 4.141 \\
Treonina (mg/d) & 6.394 & 2.639 & 2.570 \\
Triptofano (mg/d) & 1.744 & 793 & 780 \\
Cálcio (mg/d) & 1.668 & 462 & 483 \\
Ferro (mg/d) & 25 & 14 & 14 \\
Vit. B1 (mg/d) & 2 & 0,98 & 1,0 \\
Vit. B2 (mg/d) & 2 & 1,04 & 0,99 \\
Niacina (mg/d) & 51 & 28 & 28 \\
Vit. C (mg/d) & 350 & 69 & 63 \\
& & & \\
\hline
\end{tabular}

* Fundaçāo IBGE ${ }^{23}$ (1979)

estudada composta de indivíduos supostamente inteligentes, cooperativos e motivados. Esses três aspectos facilitam a aplicação do método e diminuem a ocorrência de erros ${ }^{42}$. A concordância estatística entre os resultados de ingestão alimentar obtidos nos dois diferentes questionários permitiu a escolha dos dados do método recordatório de 24 horas como representativos da ingestão dos atletas (Tabela 3 ). Restaria então a oportunidade de analisar essa ingestão dos indivíduos enquanto cidadãos e, posteriormente, como atletas.

Enquanto cidadãos, vivendo nas cidades de São Paulo ou do Rio de Janeiro, comparativamente ao consumo de nutrientes por comensal/dia levantado pelo IBGE ${ }^{23}$, nota-se que os nadadores apresentaram ingestão alimentar bem acima da média populacional daquelas cidades (Tabela 7). Entretanto, no aspecto qualitativo, verifica-se que os alimentos mais referidos, no consumo diário, pelos atletas (Tabela 4), são também os mais consumidos pela população daquelas áreas metropolitanas ${ }^{24}$. As maiores diferenças são notadas em relação às bebidas já que as mais consumidas pela população são cerveja e Coca-Cola ${ }^{24}$, enquanto que os atletas ingeriram sucos naturais e vitaminas de frutas, o que reflete, sem dúvida, um melhor conhecimento sobre nutrição e boa educação alimentar.
Pesquisas outras também demonstraram que o padrão alimentar de atletas, de diferentes modalidades esportivas, é muito semelhante ao da população, como um todo, com exceção do maior aporte calórico total ${ }^{37,39}$. No presente trabalho, essa diferença correspondeu quase ao dobro (Tabela 7), sendo que a ingestão calórica total dos atletas assim como a dos macronutrientes foram semelhantes às descritas, pela literatura, para nadadores ${ }^{3,8,25,32,39}$.

Indubitavelmente, o motivo dos nadadores apresentarem aporte calórico tão alto está relacionado ao seu elevado gasto energético diário, em função da elevada carga de treinamento físico ${ }^{39}$. É estimado que o gasto energético de nadadores possa variar de $47-85 \mathrm{Kcal} / \mathrm{kg}$ de peso/ $\mathrm{dia}^{13}$. No presente trabalho pôde ser estimada uma ingestão calórica média de $60 \mathrm{Kcal} / \mathrm{kg} / \mathrm{dia}$, para o sexo masculino.

O elevado consumo energético dos atletas tem que ocorrer no exíguo período em que não esteja treinando ou dormindo. O cumprimento dessa tarefa, dentro das 3 grandes refeições, é difícil ${ }^{47}$, que faz com que recorram, invariavelmente, aos lanches de alta densidade calórica ${ }^{16}$. No presente trabalho, os lanches responderam por $25-28 \%$ do consumo energético diário. Portanto, os lanches constituem via importante de aporte energético, evitando a ingestão de refeições volumosas, as quais prejudicam o desempenho atlético ${ }^{16}$.

Dentre os grupos de alimentos consumidos, os cereais foram os que mais contribuíram para o aporte energético, em ambos os sexos (Figura 1), o que também é descrito pela literatura ${ }^{16}$.

O consumo de glicidios pelos atletas, em treinamento intenso, deve ser de $55-65 \%$ do consumo energético total ${ }^{16}$, sendo que $70 \%$ seria a taxa recomendada para assegurar um estoque adequado de glicogênio $^{38}$. Segundo Costill ${ }^{11}$, a ingestão de glicídios por nadadores, treinando intensamente duas vezes ao dia, deveria ser de 550-800 g/dia ou 8,5$12,3 \mathrm{~g} / \mathrm{kg}$ de peso/dia. Entretanto, reconhece esse autor, em outra publicação ${ }^{12}$, que o consumo de glicídios por nadadores é usualmente baixo, compreendendo apenas $40-50 \%$ do aporte energético diário, o que pode comprometer o estoque de glicogênio muscular e, conseqüentemente, o desempenho físico. No presente trabalho, o consumo de glícidios das nadadoras foi de 298-374 g/dia (Tabela 3 ) e não atingiu o ideal mencionado acima. 
Além dos glicídios, os lipídios também constituem substrato energético importante no desempenho atlético. Além de gerar mais energia por unidade de massa, a oxidação dos ácidos graxos tem efeito poupador do glicogênio muscular ${ }^{50}$. Mesmo assim, não se recomenda dieta hiperlipídica a atletas ${ }^{29}$. Em geral, sugere-se que a ingestão dos lipidios seja limitada a $30-35 \%$ da ingestão calórica total ${ }^{25}$.

A ingestão lipídica, observada no presente trabalho, correspondeu a $34,4 \%$ e $35 \%$ da ingestão calórica total, para o sexo masculino e feminino, respectivamente (Tabela 6 ). Este valor coincide com o aconselhado (35\%) pelo DHSS $^{14}$ e está acima do valor de $30 \%$ preconizado pelo $\mathrm{WHO}^{49}$. De qualquer forma, a ingestão lipídica observada foi bastante próxima e até mesmo menor do que a descrita pela literatura para nadadores do sexo masculino $8,25,32$ ou feminino $3,8,39$.

Também em relação à participação da gordura saturada na ingestão calórica total, os dados do presente trabalho (Tabela 6 ) superaram o limite de $10 \%$ preconizados pela $\mathrm{WHO}^{49}$, mas situaram-se abaixo dos $15 \%$ aconselhados pelo DHSS ${ }^{14}$.

Com relação à ingestão dos ácidos graxos insaturados, tanto poli como monoinsaturados (Tabela 6), os nadadores do presente trabalho situaram-se bem abaixo do limite máximo aconselhado pela $\mathrm{WHO}^{49}$ que foi de $10 \%$ para os poliinsaturados e de $10-15 \%$ para os monoinsaturados.

O desbalanceamento da ingestão poliinsaturado/saturado resultou em queda do valor da relação para 0,25 e 0,24 , respectivamente para os sexos masculino e feminino. Esses valores correspondem a cerca de $50 \%$ daquele aconselhado para população européia ${ }^{28}$ que foi de 0,50 e bem abaixo da proporção de 1,0 estabelecida como ideal pela $\mathrm{WHO}^{49}$. As desvantagens da ingestão lipídica predominantemente saturada por parte de um atleta adaptado a exercício de resistência, como os nadadores aqui estudados, são questionáveis. Assim, merecem melhor reflexão as eventuais vantagens de uma menor peroxidação lipídica, pela menor ingestão de ácidos graxos poliinsaturados em atmosfera rica de oxigênio como a do corpo desses atletas $^{29}$.

A ingestão diária de $300 \mathrm{mg}$ de colesterol aconselhada pela WHO foi superada por mais de $75 \%$ dos rapazes e mais de $50 \%$ das moças.
Assim, do ponto de vista lipídico, os nadadores apresentaram ingestão caracterizada como ligeiramente elevada no seu global, de composição predominante em gordura saturada e rica em colesterol.

O consumo protéico diário preconizado para atletas, é variável. Assim, há autores relatando que o mesmo deve ser de no máximo $1,5 \mathrm{~g} / \mathrm{kg}$ de peso/dia nos periodos de treinamento intenso e de competição ${ }^{16}$, ou entre 1,5 a $1,8 \mathrm{~g} / \mathrm{kg}$ de peso/dia para suprir a possivel necessidade extra de certos aminoácidos essenciais ${ }^{30}$.

A utilização de proteínas com finalidade energética ocorre nos exercícios intensos de longa duração (horas), chegando inclusive a negativar o balanço nitrogenado ${ }^{31}$. Nessas condições, os principais aminoácidos fornecedores de cadeia carbônica para a via energética são os aminoácidos de cadeia ramificada, tendo a leucina como contribuinte majoritário ${ }^{31}$. As necessidades diárias deste aminoácido situam-se em torno de 30 a $40 \mathrm{mg} / \mathrm{kg}$ de peso, dependendo da metodologia empregada ${ }^{51}$. No presente trabalho a ingestão média foi de 14.537 $\mathrm{mg} / \mathrm{dia}$ ( $197 \mathrm{mg} / \mathrm{kg}$ de peso) para o sexo masculino e $6.206 \mathrm{mg} / \mathrm{dia}$ (103 mg/kg de peso) para o sexo feminino. De maneira semelhante, as necessidades de lisina (30-43 mg/kg de peso/dia), treonina (15-22 $\mathrm{mg} / \mathrm{kg}$ de peso/dia), valina $(20-25 \mathrm{mg} / \mathrm{kg}$ de peso/dia) e metionina (16-17 $\mathrm{mg} / \mathrm{kg}$ de peso/dia) também foram plenamente preenchidas 51 .

Há autores que sugerem a taxa de $2 \mathrm{~g}$ de proteínas/kg de peso/dia como forma de prevenir a destruição das proteínas sangüineas, dentre as quais a hemoglobina, reduzindo assim as chances de anemia durante a hipertrofia muscular pelo treinamento físico intenso ${ }^{52}$. Há uma noção generalizada dentre os atletas que as dietas contendo grandes quantidades de carnes são necessárias à adaptação ao treinamento físico ${ }^{52}$ e obtenção de bom desempenho atlético ${ }^{16}$ em função do aumento da massa muscular, pela maior síntese das proteinas miofibrilares nas células musculares exercitadas ${ }^{10}$. Entretanto, em contraposição $\mathrm{a}$ isso, há o consenso fisiológico que a atividade física crônica promove melhora na economia nitrogenada. Assim, atletas treinados apresentam requerimento protéico até menor que o indivíduo sedentário, para manter um mesmo balanço de nitrogênio, desde que em presença de aporte energético adequado ${ }^{6}$. 


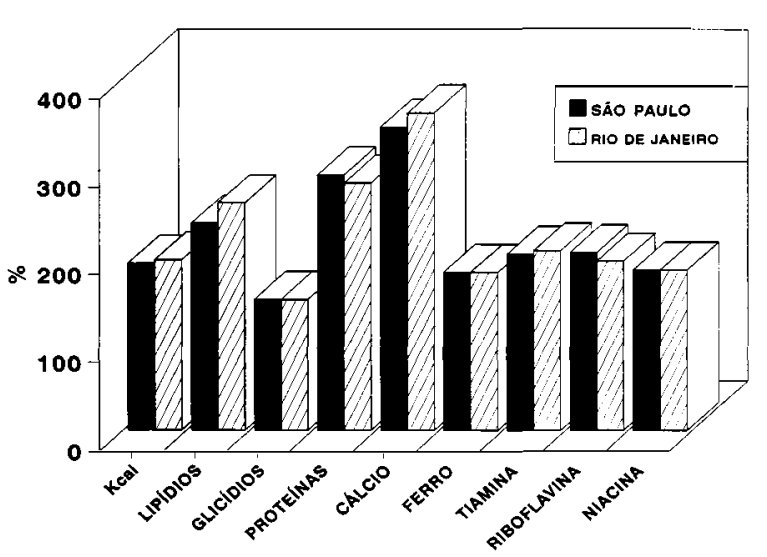

Figura 2. Consumo médio diário de energia e nutrientes dos nadadores em relação (\%) do referido pelo IBGE (1979) para as populações metropolitanas de São Paulo e do Rio de Janeiro.

De qualquer forma, deve ser enfatizado que o metabolismo protéico durante o exercício físico sofre alterações induzidas por vários fatores incluindo intensidade, duração e tipo de exercício, como também, treinamento prévio e consumo protéico-energético além dos bem estudados efeitos do sexo e idade do indivíduo exercitado ${ }^{7}$. Mesmo assim, mais pesquisas são necessárias para o melhor estabelecimento dos requerimentos protéicos para os atletas ${ }^{25}$, procurando, desta forma, desmistificar a proteína como nutriente mágico, $e$ induzir o atleta a obter suas necessidades protéicas, dentro dos alimentos naturais ${ }^{16}$.

No presente trabalho, o consumo médio de proteínas pelos nadadores foi de 2,3 a $3,3 \mathrm{~g} / \mathrm{kg}$ de peso/dia (Tabela 3), bem acima do ideal para atletas, mas, mesmo assim, abaixo do descrito por outros autores envolvendo nadadores ${ }^{8}$. A distorção nutricional mais evidente desta grande ingestão protéica pode ser vista na Tabela $6 \mathrm{em}$ que as proteinas apresentaram participação elevada (17-19\%) no aporte energético diário, em prejuízo da participação dos glicídios, o que foi observado também por outros autores ${ }^{8}$.

A análise da ingestão dos micronutrientes, pelos nadadores, apresenta algumas dificuldades quanto ao padrão de referência a ser utilizado. Em

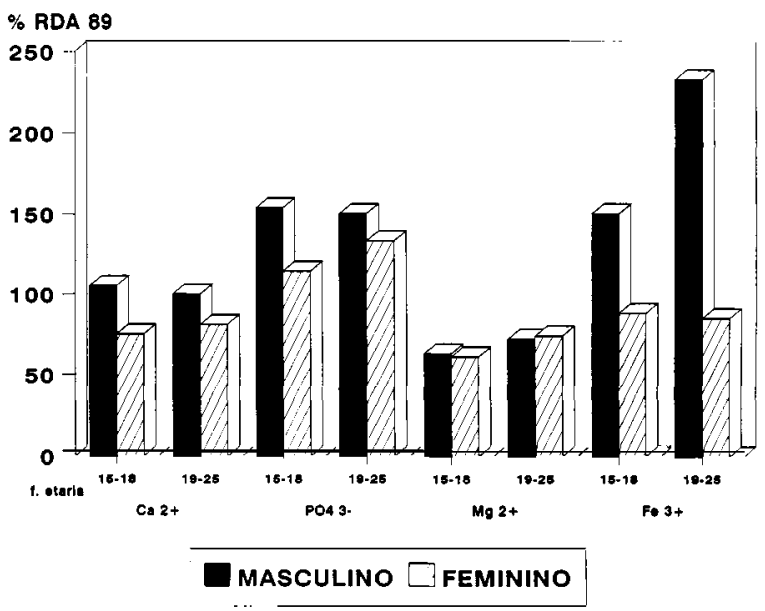

Figura 3. Adequaçäo da ingestão mineral dos nadadores ao padrāo estabelecido pela "Recommended Dietary Allowances" (1989), uniformizados por $1.000 \mathrm{Cal}$.

relação aos padrões nacionais, como já mencionado anteriormente, os nadadores apresentam ingestão acima da descrita pelo IBGE (Figura 2) para aquelas populações metropolitanas. Em relação ao padrão populacional americano, o uso da "Recommended Dietary Allowances" (RDA) ${ }^{35}$ é limitado no fato dos dados serem fornecidos em relação ao homem ou mulher referência e não ao atleta (que é mais pesado e não apenas moderamente ativo). Para contornar essa situação, Hansen \& Wyse ${ }^{27}$ sugeriram a expressão dos dados do RDA por $1.000 \mathrm{Kcal}$ ingeridas. Usando esse sistema, os dados do presente trabalho mostraram inadequações de minerais para o sexo feminino em cálcio, magnésio e ferro, e para o sexo masculino apenas em magnésio (Figura 3). $P a r a$ as vitaminas as ingestões inadequadas foram mínimas sendo de vitamina $D$ para ambos os sexos de ambas faixas etárias, vitamina $A$ para os juvenis, vitamina $B_{1}$ para as nadadoras juvenis e nadadores seniors e vitamina $B_{6}$ para os nadadores juvenis e nadadoras seniors (Figura 4).

É descrito que os nadadores representam grupo de atletas predispostos a apresentarem comprometimento nutricional pela grande perda de micronutrientes pela pele, pelo aceleramento deste processo no prolongado contacto desta com a água durante os treinamentos ${ }^{32}$. 
Chen e col. ${ }^{8}$ mencionam a ingestão insuficiente de cálcio, ferro, tiamina e riboflavina como um dos maiores problemas nutricionais das atletas adolescentes, o que pode ser interpretada também no presente trabalho (Figuras 3 e 4 ). No caso do ferro, a baixa ingestào (por $1.000 \mathrm{Kcal}$ ) ocorreu também para as nadadoras seniors (juntamente com a inadequação do folato). $O$ consumo reduzido de ferro, em atletas, é referido também por outros autores ${ }^{17}$.

A ingestão diária de ferro (mg/dia) das nadadoras (Tabela 3) foi semelhante e em alguns casos até superior à descrita pela literatura ${ }^{3}$. A quantidade diária recomendada para essa faixa etária é 15 $\mathrm{mg} / \mathrm{dia}^{35}$.

A "anemia do esporte" tem sido observada em atletas do sexo feminino, durante treinamento para exercicios de resistência como ciclismo e natação ${ }^{9}$. A etiologia exata dessa anemia é desconhecida, existindo hipóteses que atribuem a deficiência de ferro à sua maior perda ou aos baixos níveis de ferritina sérica ${ }^{26}$.

Em relação ao magnésio, os resultados referidos a $1.000 \mathrm{Kcal}$ estão abaixo dos $100 \%$ de adequadação (Figura 2), sendo sua ingestão (em mg -

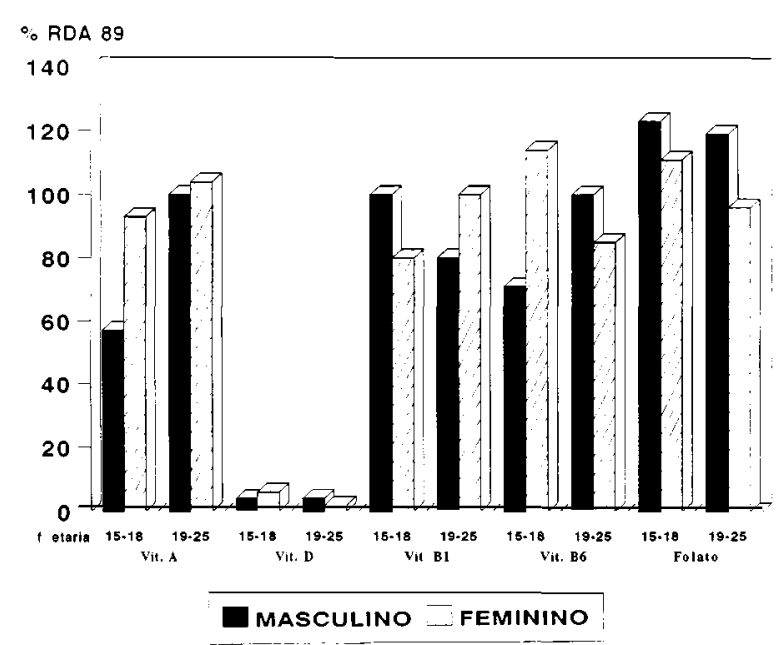

Figura 4. Adequação da ingestão vitamínica dos nadadores ao padrão estabelecido pela "Recommended Dietary Allowances"(1989), uniformizados por $1.000 \mathrm{Cal}$.
Tabela 3) bastante semelhante à descrita por outros trabalhos envolvendo nadadores ${ }^{3,8}$. Comportamentos semelhantes mostraram as vitaminas hidrossolúveis $B_{1}, B_{6}$ e folato (Figura 4 e Tabela 3$)^{3,8,39}$. Assim, parece evidente que mesmo o sistema de referir a ingestão de micronutrientes por $1.000 \mathrm{Kcal}$ é falho para os atletas visto que nem todas as fontes calóricas (ex. glicídeos) contém todos os micronutrientes, como o caso da vitamina $D$, magnésio e cálcio. Assim, uma elevada ingestão de calorias glicídicas aumentaria apenas o denominador da relação, diluindo a ingestão real do micronutriente. Confirmando esse raciocínio, há a situação da ingestão de cálcio, observada como sendo em redor de $2 \mathrm{~g}$ no sexo masculino e um grama no sexo feminino (Tabela 3), sendo que a RDA é de 0,8 $\mathrm{g} / \mathrm{dia}^{35}$. Além disso, há o problema crônico das tabelas de composição dos alimentos, consultadas para a análise quantitativa dos nutrientes existentes nas dietas. Essas tabelas são constantemente modificadas, uma vez que a cada metodologia analítica nova, e empregada, há a mudança na concentração do nutriente no alimento ${ }^{17}$.

Dentro da amostra estudada notou-se que as atletas foram as que apresentaram maior inadequação em relação aos demais dados da literatura. Assim, elas apresentaram ingestão calórica baixa ${ }^{11}$ de apenas $2.600 \mathrm{Kcal}$ e inadequação de cálcio e ferro ${ }^{35}$, sendo que as calorias oriundas dos cereais e laticínios, ingeridos, foi menor que a dos nadadores (Figura 1). Outros autores estudando os hábitos alimentares de mulheres adolescentes, demonstraram que a qualidade nutricional das suas dietas era inferior a dos rapazes, sendo que a restrição nutricional estaria relacionada ao objetivo da obtenção de melhor aparência física ${ }^{33,48}$. Além disso, refeiçōes para controle de peso são prevalentes entre atletas de diferentes modalidades esportivas ${ }^{45}$, o que poderia ser aplicado aos resultados do presente trabalho.

Os nadadores estudados mostraram, enquanto indivíduos, hábitos dietéticos semelhantes e uma ingestão de nutrientes superior a média dos demais cidadãos morando na mesma área metropolitana. Isto mostra mais uma vez que as necessidades dietéticas do atleta não são diferentes do indivíduo não atleta com exceção do total calórico e água ${ }^{11}$. Uma dieta bem balanceada pode fornecer os nutrientes necessários aos atletas, dispensando-se a suplementação medicamentosa, a 
qual deve ser restringida apenas aos atletas que apresentamdeficiênciadenutrientes,comcomprovaçãdbioquímica ${ }^{47}$.

SOARES, E.A. et al. [Anthropometric and dietetic study of competitive swimmers of metropolitan areas of southeastern Brazil]. Rev. Saúde Pública, 28:9-19, 1994. The daily food intake and alimentary frequency of competitive swimmers of two clubs representative of the two largest cities in Brazil (S.Paulo and Rio de Janeiro) were studied. The 30 males and 37 females studied belonged to the swimming categories "junior" (15-17 yrs old) and "senior" (18-25 yrs old). Food intake obtained from self-register and 24 hour-recall showed similar results and therefore the 24 hour-recall was used for comparisons with the literature. Ages within both sexes were anthropometrically similar. The most frequently eaten foodstaffs were similar to those quoted by the metropolitan population of the respective areas. Moroever, the athletes from both cities reported similar food-supplements. The energy intake was found to average almost double the estimated value for the respective metropolitan populations, but were similar to results obtained for swimmers all over the world. Snacks between meals supplied $25-28 \%$ of the overall energy intake. The main caloric source were cereals. However, despite their contribution of almost $50 \%$ of the total energy intake, carbohydrates attained a level of only $55-60 \%$ of that recommended for competitive athletes. On the other hand, the protein intake found $(2.5-3.0 \mathrm{~g} / \mathrm{kg} /$ day $)$ exceeded the recommended values by $100 \%$. The fat intake particularly of satured fat, was also considered high. The swimmers' intake of micronutrients was well abone that quoted by the regular population of these metropolitan areas, when related to the caloric intake, but the values of $\mathrm{Mg}, \mathrm{Fe}$ and vitamins $A$ and $D$ were somecohot lower than those recommended. This is due to the higers energy intake of the swimmers. From these overall results it may be concluded that the alimentary pattern of the swimmers studied does not differ greatly from that of the local population, being distinguished by its higher and more frequent intake of caloric foods rather than by its qualitative aspects.

Keywords: Food habits, classification. Diet surveys. Swimming.

\section{Referências Bibliográficas}

1. ANSELMO, M.A.C. Antropometria: aspectos históricos e visão critica. Cad Nutr., 3:11-25, 1991.

2. ANSELMO, M.A.C.; BURINI, R.C.; ANGELELI, A.Y.O.; MOTA, N.G.S.; CAMPANA, A.O. Avaliação do estágio nutricional de individuos adultos sadios de classe média: ingestão energética e protéica, antropometria, exames bioquímicos do sangue e testes de imunocompetência. Rev.Saúde Pública, 26:46-53, 1992.
3. BARR, S.I. Nutrition knowledge of female varsity athletes and university students. J.Am. Diet. Assoc., 87:1660-4, 1987.

4. BEATON, G.H.; MILNER, J.; McGUIRE, V.; FEATHER, T.E; LITTLE, J.A. Sources of variances in 24-hour dietary recall data: implications for nutrition study design and interpretation. Carbohydrates sources, vitamins, and minerals. Am. J. Clin. Nutr., 37:986-95, 1983.

5. BROZEK, J. \& KEYS, A. The evaluation of leannes-fatness in man: nonns and interrelationship. Br. J. Nutr., 5:194-206, 1951.

6. BUTTERFIELD, G.E. \& CALLOWAY, D.H. Physical activity improves protein utilization in young men. $B r . J$. Nutr., 51:171-84, 1984.

7. BUTTERFIELD, G.E. Whole-body protein utilization in humans. Med. Sci. Sports Exerc., 19(Suppl. 5):S157-65, 1987.

8. CHEN, J.D.; WANG, J.F; LI, K.J.; ZHAO, Y.W.; WANG, S.W.; JIAO, Y; HOU, X.Y. Nutritional problems and measures in elite and amateur athletes. Am.J. Clin. Nutr., 49(Suppl. 5):S1084-9, 1989.

9. CLEMENT, D.B.; ASMUNDSON, R.C; MEDHURST, C.W. Hemoglobin values: comparative survey of the $1976 \mathrm{Ca}-$ nadian Olympic team. Can. Med. Assoc. J., 117:614-6, 1977.

10. CONSOLAZIO, C.F.; JOHNSON, H.L.; NELSON, R.A.; DRAMISE, J.G; SKALA, J.H. Protein metabolism during intensive physical trainning in the young adult. Am. J. Clin. Nutr., 28:29-35, 1975.

11. COSTILL, D.L. Carbohydrates for exercise: dietary demands for optimal perfonmance. Int. J. Sports Med., 9:1-18, 1988.

12. COSTILL, D.L.; HINRICHS, D.; FINK, W.J; HOOPES, D. Muscle glycogen depletion during swimming interval training. J. Swim. Res., 4:15-8, 1988.

13. COSTILL, D.L.; SHERMAN, W.M.; FINK, W.K.; MARESH, C.; WITTEN, M; MILLER, J.M. The role of dietary carbohydrates in muscle glycogen resynthesis after strenuous running. Am. J. Clin. Nutr., 34:1831-6, 1981.

14. DEPARTMENT OF HEALTH AND SOCIAL SECURITY. Diet and cardiovascular disease. Committee on medical aspects of food policy report of the panel on diet in relation to cardiovascular disease. London, H.M. Stationery Office, 1984 .

15. DOWDY, R.P. \& BURT, J. Effect of intensive long-term training on copper and iron nutritive in man. [Abstr.]. Fed. Proc., 39: 786, 1980.

16. ERP-BAART, A.M.J. VAN; SARIS, W.H.M.; BINKHORST, R.A.; VOS, J.A.; ELVERS, J.W.H. Nationwide survey on nutritional habits in elite athletes. Part I. Energy, carbohydrate, protein and fat intake. Int. J. Sports Med, 10 (Suppl. 1):S3-10, 1989.

17. ERP-BAART, A.M.J. VAN; SARIS, W.H.M.; BINKHORST, R.A.; VOS, J.A; ELVERS, J.W.H. Nationwide survery on nutritional habits in elite athletes. Part II. Mineral and vitamin intake. Int. J. Sports Med, 10(Suppl. 1):S11-6, 1989.

18. ESCOLA PAULISTA DE MEDICINA. Centro de Informática em Saúde. Sistema de avaliação nutricional. São Paulo, 1990.

19. FAULKNER, J.A. Physiology of swimming and diving. In: Falls, H. Exercise physiology. Baltimore, Academic Press, 1968. p. 415-46.

20. FIDANZA, F. Sources of error in dietary surveys. Bibl. Nutr. Diet., 20:105-13, 1974.

21. FOOD AND DRUG ADMINISTRATION. Vitamin and mineral drug products for over-the-counter human use. Fed Regist., 44:16126-201, 1979. 
22. FOOD AND DRUG ADMINISTRATION. Vitamins, minerals and FDA. FDA Consumer, 7:18-9, 1973.

23. FUNDAÇÃO IBGE. Perfil estatístico de crianças e mães no Brasil. Rio de Janeiro, 1979.

24. FUNDAÇÃO IBGE. Pesquisa de orçamentos familiares 1987/88, Rio de Janeiro, 1991 (Consumo Alimentar Domiciliar "per capita", $n^{2} 2$ ).

25. GRANDJEAN, A.C. Macronutrient intake of US athletes compared with the general population and recommendations made for athletes. Am. J. Clin. Nutr, 49 (Suppl. 5):\$10706,1989 .

26. HALLBERG, L. \& MAGNUSSON, B. The etiology of "sports anemia". Acta Med. Scand., 216:145-8, 1984.

27. HANSEN, R.G. \& WYSE, B.W. Expression of nutrient allowances per 1,000 kilocalories. J. Am. Diet. Assoc., 76:2237, 1980.

28. JAMES, W.P.T. A European view of nutrition and emerging problems in the Third World. Am. J. Clin. Nutr., 49 (Suppl. 5):S985-92, 1989.

29. JENKINS, R.R. Free radical chemistry: relationship to exercise. Sports med., 5:156-70, 1988.

30. LEMON, P.W.R. \& NAGLE, F.J. Effects of exercise on protein and aminoacid metabolism. Med. Sci. Sports Exerc., 13:141-9, 1981

31. LEMON, P.W.R. Protein and exercise uptade 1987. Med Sci. Sports Exerc., 19(Suppl. 5):S179-90, 1987.

32. LUKASKI, H.C.; HOVERSON, B.S.; GALLAGHER, S.K.; BOLONCHUK, W.W. Physical training and copper, iron, and zinc status of swimmers. Am. J. Clin. Nutr., 51:1093-9, 1990.

33. MaC DONALD, L.A; WEARRING, G.A; MOASE, O. Factors affecting the dietary quality of adolescent girls. $J . A m$. Diet. Assoc., 82:260-3, 1983.

34. MARR, J.W. \& HEADY, J.A. Within-and between-person variation in dietary surveys: number of day needed to classify individuals. Hum. Nutr. Appl. Nutr., 40A:347-64, 1986.

35. NATIONAL RESEARCH COUNCIL FOOD AND NUTRITION BOARD. Recommended dietary allowances. $10^{\text {th }}$ ed. Washington, D.C., National Academy of Sciences, 1989.

36. NIEMAN, D.C.; BUTLER, J.V.; POLLETT, L.M.; DIETRICH, S.J.; LUTZ, R.O. Nutrient intake of marathon runners. J. Am. Diet. Assoc., 89:1273-8, 1989.

37. PERRON, M. \& ENDRES, J. Knowledge, attitudes and dietary practices of female athletes. J. Am. Diet. Assoc., 85:573-6, 1985.

38. SHERMAN, W.M. Carbohydrate, muscle glycogen, and improved performance. Phys. Sportsmed, 15:157-64, 1987.
39. SHORT, S.H. \& SHORT, W.R. Four-year study of university athletes' dietary intake. J. Am. Diet. Assoc., 82: 632-45, 1983.

40. SILVA, G.B. Critérios de estratificação social. Rev. Saúde Pública, 15:38-45, 1981.

41. SOARES, E.A.; PORTELLA, E.S; ISHI, M. Relaçāo de medidas caseiras de 320 alimentos e respectivas gramagens. São Paulo, 1991 (Ceane - Série Divulgação Científica, 1).

42. STEIN, T.P.; SCHLUTER, M.D; DIAMOND, C.E. Nutrition protein turnover, and physical activity in young women. Am. J. Clin. Nutr., 38:223-8, 1983.

43. TODD, K.S.; HUDES, M; CALLOWAY, D.H. Food intake measurement: problems and approaches. Am. J. Clin. Nutr, 37:139-46, 1983.

44. WELCH, P.K.; ZAGER, K.A.; ENDRES, J.; POON, S.W. Nutrition education, body composition, and dietary intake of female college athletes. Phys. Sportsmed., 15:63-74, 1987.

45. WERBLOW, J.A.; FOX, H.M.; HENNEAMN, A. Nutritional knowledge, attitudes, and food pattems of women athletes. J. Am. Diet. Assoc., 73:242-5, 1978.

46. WILMORE, J.H. Body composition in sport and exercise: directions for future research. Med. Sci. Sports Exerc., 15:21-31, 1983.

47. WILMORE, J.W. \& FREUND, B.J. Nutritional enhancement of athetic performance. Nutr. Abst. Rev., 54:1-16, 1984.

48. WOODWARD, D.R. What sort of teenager has low intakes of energy nutrientes? Br. J. Nutr., 53:241-9, 1985.

49. WORLD HEALTH ORGANIZATION. Prevention of corona$r y$ heart disease. Geneva, World Health Organization, 1982.

50. WRIGHT, E.D. \& PAIGE, D.M. Lipid metabolism and exercise. Clin. Nutr., 7:28-32, 1988.

51. YOUNG, V.R.; BIER, D.M.; PELLET, P.L. A theoretical basis for increasing current estimates of the aminoacid requirements in adult man, with experimental support. Am. $J$. Clin. Nutr., 50:80-92, 1989.

52. YOSHIMURA, H.; INOUE, T.; YAMADA, T.; SHIRAKI, K. Anemia during hard physical training (sports anemia) and its causal mechanism with special reference to protein nutrition. World Rev. Nutr. Diet., 35:1-86, 1980.

Recebido para publicaçāo em 3.3.1993 Reapresentado em 18.10.1993 Aprovado para publicação em 31.1.1994 